\title{
Correction to: Influence of oral anticoagulation on success rates and risk of bleeding events after iStent inject implantation combined with phacoemulsification
}

\author{
Randolf A. Widder ${ }^{1,2}$ - Alexandra Lappas ${ }^{2}$ - Corinna Rennings ${ }^{1}$ - Matthias Hild ${ }^{1}$. Gernot F. Roessler ${ }^{1,3}$. \\ Thomas S. Dietlein ${ }^{2}$
}

Published online: 24 September 2020

(C) Springer-Verlag GmbH Germany, part of Springer Nature 2020

\section{Correction to: Graefe's Archive for Clinical and Experimental Ophthalmology https://doi.org/10.1007/s00417-020-04894-3}

The published online version contains mistake as the author's first name and last name have been interchanged as "Hild Matthias" instead of "Matthias Hild". The correct presentation is given above.

The original article has been corrected.

Publisher's note Springer Nature remains neutral with regard to jurisdictional claims in published maps and institutional affiliations.

The online version of the original article can be found at https://doi.org/ 10.1007/s00417-020-04894-3

Randolf A. Widder

r.widder@martinus-duesseldorf.de

1 Department of Ophthalmology, St. Martinus-Krankenhaus Düsseldorf, Gladbacher Strasse 26, 40219 Düsseldorf, Germany

2 Center of Ophthalmology, University of Cologne, Kerpener Strasse 62, 50937 Köln, Germany

3 Department of Ophthalmology, RWTH Aachen, Pauwelsstrasse 30, 52074 Aachen, Germany 